\title{
Surgery is Still Alive in Descending Thoracic Aortic Aneurysm
}

\author{
Chaud Germán J, Filippa Pablo A, Wainscheinker Ezequiel, Paladini Guillermo and *Martínez Colombres \\ Moisés A \\ Department of Cardiac Surgery, Hospital Privado Universitario de Córdoba, Córdoba, Argentina
}

Submission: January 19, 2017; Published: January 31, 2017

*Corresponding author: Martínez Colombres Moisés Alejandro, Hospital Privado Universitario Centro Médico de Córdoba, Naciones Unidas 346 , (5016) Córdoba, Tel: +54 351 4688236; Fax: +54 351 4688228; Email: alemartinezc64@gmail.com

\section{Abstract}

Introduction: The surgical treatment of descending thoracic aortic aneurysm is changing in response to the advent of endovascular treatment; however, not all of patients are candidates for it. The choice of the surgical technique isessential at the moment of taking these patients to conventional surgery.

Case Report: A 25-year-old female patient with a symptomatic descending thoracic aortic aneurysm of 54 x $53 \mathrm{~mm}$ after coarctation surgery of the aorta in childhood who was operated in a conventional manner through complete circulatory arrest. She was discharged at 5 postoperative days without central or peripheral neurological complications.

Conclusion: Aneurysm after aortic coarctation surgery is a late complication known. The most serious complications of conventional repair of these have been neurological, both central and peripheral. With the technique proposed by Dr. Chard, we demonstrate once again that surgery can be performed with low morbidity and mortality.

Keywords: Descending aortic aneurysm; Coarctation of the aorta; Circulatory arrest; Adults

\section{Introduction}

Surgical treatment for descending thoracic aneurysm is changing drastically in response to the advent of endovascular treatment. The endoprosthesis has been used to treat DTA with favorable results.

However, replacement by conventional surgery is still the standard treatment for DTA. There are several surgical strategies for DTA such as single clamping, distal perfusion by left heart bypass, hypothermic circulatory arrest and partial cardiopulmonary bypass [1].

\section{Case Report}

A 25-year-old female patient with a history of coarctation of the aorta operated at the age of 6 presents with a symptomatic descending thoracic aortic aneurysm (chest pain) of $54 \times 53 \mathrm{~mm}$ in diameter and $75.4 \mathrm{~mm}$ in length by MRI, which involves the Subclavian artery (Figure 1). Due to the diameter of the proximal neck of $17.5 \mathrm{~mm}$ and impossibility of endovascular treatment in our center, conventional surgical treatment was decided.

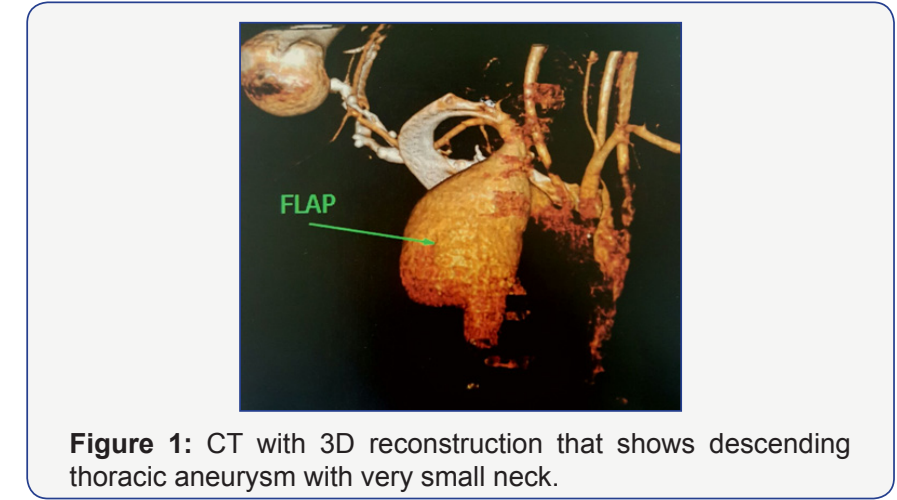

Surgical Technique

The patient was anesthetized with an endotracheal double lumen tube, positioned in the right lateral position, keeping the torso at $45^{\circ}$ and the legs at $90^{\circ}$. The thoracotomy was performed at the level of the 4 a intercostal space. Left common femoral venous cannulation was performed guided to the right atrium 
by TEE and then femoral arterial cannulation on the same side. A thorough dissection of the left lung with large adhesions was performed until the DTA was reached and then CPB was started, during which the patient cooled until reaching $17^{\circ} \mathrm{C}$, after which the heart was stopped without arrhythmia. Circulatory arrest was started. The aneurysm was sectioned longitudinally. The left subclavian artery was identified as the reason for which a descending aorta was replaced with Dacron prosthesis of 18 $\mathrm{mm}$. After that, the subclavian artery was reinserted by the interposition of $8 \mathrm{~mm}$ Dacron prosthesis.

Subsequently raffia of the aneurysmal sac was performed on the implanted prosthesis. After all the anastomosis, the patients were gradually re-heated and the onset of CPB started again. Surgery without aortic clamping was performed by means of a circulatory arrest of 52 minutes and total time of ECC of 150 minutes. The patient was extubated within the first 8 hours after surgery in the intensive care unit, without central or peripheral neurological complication. Normal postoperative course and she was discharged after 5 days. Currently, he performs activities according to his age and the correct repair of his initial aneurysm was verified by CT scan with contrast at 90 days postoperatively (Figures 2 \& 3).

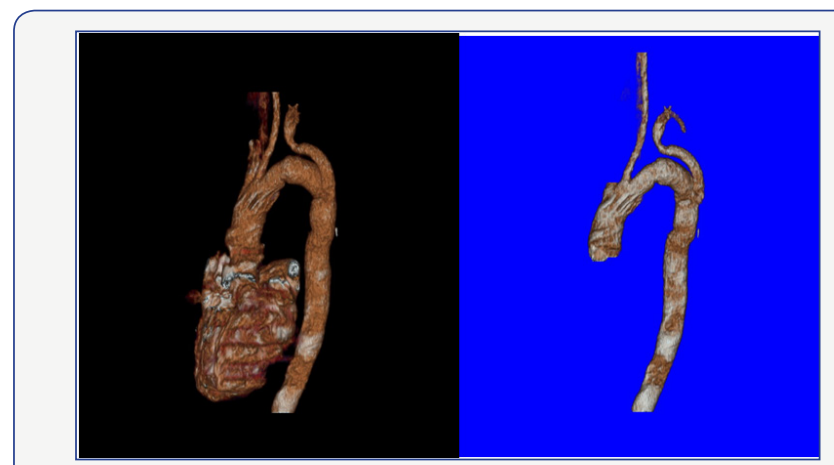

Figures 2 \& 3: CT with 3D reconstruction that shows descending thoracic aortic repaired and subclavian artery re-implanted.

\section{Discussion}

Despite the advances in brain protection and surgical techniques, brain damage remains a frequent complication, particularly as a cerebral infarction after aortic clamping. Different techniques such as selective cerebral perfusion, hypothermic circulatory arrest and retrograde cerebral perfusion associated with hypothermic circulatory arrest have been used in aortic arch operations [2].

The formation of aneurysm at the site of a previous coarctation repair is increasingly recognized as a late complication and is more frequently associated with the use of prosthesis repair. The incidence varies between 5 and 38\% occurring between 6 and 18 years after aortoplasty [3].

Surgical intervention of post-coarctation aortic aneurysms involves difficulties related to clamping of the aorta such as cerebral infarction, bleeding, dissection, medullary ischemia and recurrent laryngeal nerve injury, including surgical adhesions that increase the technical difficulties [4].

In our case, we decided to perform the technique proposed by Dr. Chard because of the high risk of injury of the recurrent laryngeal nerve by completely sectioning the aorta and the need of replantation of subclavian artery.

\section{Conclusion}

According to the technical difficulties that this type of surgery presents, not only the need of reoperation but also the high risk of spinal cord injury and peripheral nerves, we recommend by means of the presentation of our case, the realization of circulatory arrest and deep hypothermia, as well as longitudinal section of the aneurysm without total resection to avoid those complication, in patients who are not good candidates for TEVAR. Conventional surgery can be performed with low morbidity and mortality if the appropriate technique is used in the appropriate patient.

\section{References}

1. Minatoya K, Ogino H, Matsuda H, Sasaki H, Yagihara T, et al. (2008) Replacement of the descending aorta: Recent outcomes of open surgery performed with partial cardiopulmonary bypass. J Thorac Cardiovasc Surg 136(2): 431-435.

2. Yasuura K, Okamoto H, Ogawa Y, Matsuura A, Asakura T, et al. (1994) Resection of aortic aneurysms without aortic clamp technique with the aid of hypothermic total body retrograde perfusion. J Thorac Cardiovasc Surg 107(5): 1237-1243.

3. Matthias Roth, Peter Lemke, Markus Schonburg, Wolf-Peter Klovekorn, Erwin P Bauer (2002) Aneurysm Formation After Patch Aortoplasty Repair (Vossschulte): Reoperation in Adults With and Without Hypothermic Circulatory Arrest. Ann Thorac Surg 74(6): 2047-2050.

4. Nicholas Kang, Andrew JB Clarke, Ian A Nicholson, Richard B Chard (2004) Circulatory Arrest for Repair of Postcoarctation Site Aneurysm. Ann Thorac Surg 77(6): 2029-2033.

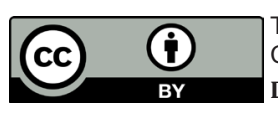

This work is licensed under Creative Commons Attribution 4.0 License DOI: 10.19080/JOCCT.2017.03.555604

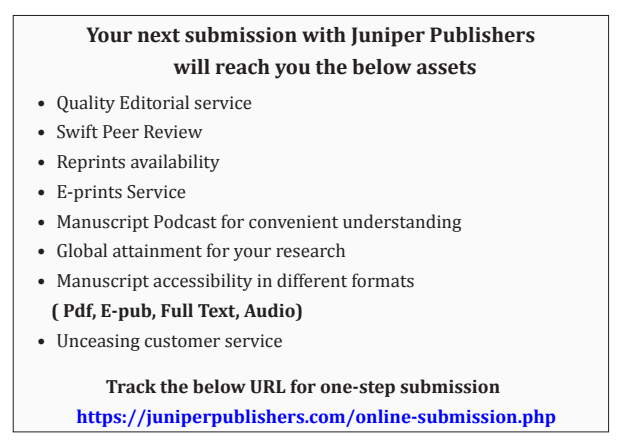

